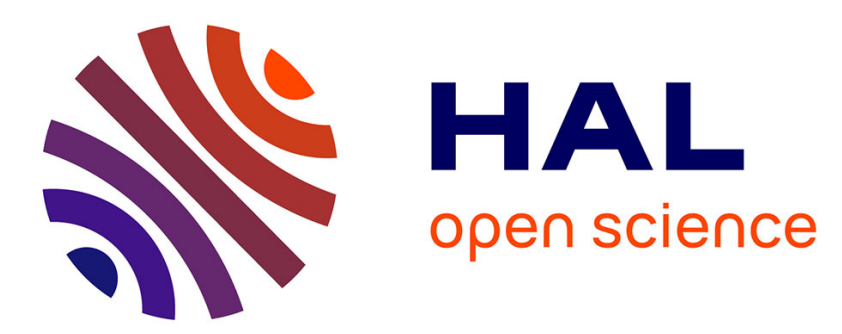

\title{
Stability Is Not Everything: The Case of the Cyclisation of a Thrombin-Binding Aptamer
}

Claudia Riccardi, Albert Meyer, Jean-Jacques Vasseur, Irene Russo krauss, Luigi Paduano, Rosario Oliva, Luigi Petraccone, François Morvan, Daniela Montesarchio

\section{To cite this version:}

Claudia Riccardi, Albert Meyer, Jean-Jacques Vasseur, Irene Russo krauss, Luigi Paduano, et al.. Stability Is Not Everything: The Case of the Cyclisation of a Thrombin-Binding Aptamer. ChemBioChem, 2019, 10.1002/cbic.201900045 . hal-02197218

\section{HAL Id: hal-02197218 https://hal.science/hal-02197218}

Submitted on 6 Nov 2020

HAL is a multi-disciplinary open access archive for the deposit and dissemination of scientific research documents, whether they are published or not. The documents may come from teaching and research institutions in France or abroad, or from public or private research centers.
L'archive ouverte pluridisciplinaire HAL, est destinée au dépôt et à la diffusion de documents scientifiques de niveau recherche, publiés ou non, émanant des établissements d'enseignement et de recherche français ou étrangers, des laboratoires publics ou privés. 


\title{
Stability is not everything: the case of the cyclization of the thrombin binding aptamer
}

\author{
Claudia Riccardi, ${ }^{a}$ Albert Meyer, ${ }^{\text {b Jean-Jacques Vasseur, }}{ }^{b}$ \\ Irene Russo Krauss, ${ }^{\text {a,c }}$ Luigi Paduano, ${ }^{\text {a,c }}$ Rosario Oliva, ${ }^{\text {a Luigi Petraccone, }}{ }^{\mathrm{a}}$ \\ François Morvan,, ${ }^{\text {,* }}$ Daniela Montesarchio ${ }^{\text {a,* }}$
}

${ }^{a}$ Department of Chemical Sciences, University of Naples Federico II, Via Cintia 21, I-80126, Napoli, Italy

${ }^{b}$ Institut des Biomolécules Max Mousseron, Univ. Montpellier, CNRS, ENSCM, Montpellier, France ${ }^{c}$ CSGI - Consorzio Interuniversitario per lo Sviluppo dei Sistemi a Grande Interfase, Via della Lastruccia 3, I-50019, Sesto Fiorentino (Fi), Italy

*Corresponding authors. E-mail address: daniela.montesarchio@ unina.it (D. Montesarchio); francois.morvan@umontpellier.fr (F. Morvan).

Aiming at novel approaches to obtain improved aptamers, we developed a cyclic TBA analogue (cycTBA) by exploiting $\mathrm{Cu}(\mathrm{I})$-assisted azide-alkyne cycloaddition. Its markedly increased serum resistance and exceptional G-quadruplex (G4) stability vs. TBA were associated to reduce thrombin inhibition, suggesting that some flexibility in TBA structure is necessary for protein recognition.

In the panorama of anticoagulant agents, inhibitors of thrombin - a "trypsin-like" serine protease with fundamental roles in blood clotting, converting soluble fibrinogen into insoluble fibrin ${ }^{1}$ - are among the most reliable and widely exploited drugs against thrombosis. The 15-mer G-rich oligonucleotide Thrombin Binding Aptamer $\left(\mathrm{TBA}_{15}\right.$ or simply TBA), carrying the sequence 5'GGTTGGTGTGGTTGG-3', is the best-characterized aptamer of thrombin. TBA has been proposed as a valuable alternative to classical thrombin inhibitors used in clinic, such as heparin, warfarin and bivalirudin, showing severe side effects and/or suffering from narrow therapeutic windows. ${ }^{2}$ Upon folding into an antiparallel, chair-like G-quadruplex structure, TBA can tightly and selectively bind the fibrinogen-binding exosite I of human thrombin, inhibiting its key functions in the coagulation cascade. ${ }^{3}$

Due to suboptimal dosing profiles, TBA did not progress to advanced clinical trials, being blocked after Phase I studies. ${ }^{4}$ Since then, a large number of TBA analogues have been synthesized carrying either backbone modifications ${ }^{5}$ or integrated into different nanosystems - including magnetic, ${ }^{6}$ gold $^{7}$ and silica nanoparticles ${ }^{8}$ - showing promising pharmacokinetic profiles, however not reaching advanced in vivo studies.

In this scenario, as a general strategy to improve the in vivo properties of TBA, we herein propose a cyclization approach to obtain a better performing TBA analogue, involving the covalent connection, via a proper flexible linker, of the 3'- and 5'-ends of the oligonucleotide strand. Two major benefits are expected upon cyclizing TBA: on one side, the absence of the $3^{\prime}$ and 5' termini should sensibly protect the oligonucleotide from nuclease degradation, thus significantly prolonging 
its in vivo half-life; on the other, the structural preorganization of the aptamer, imposed by its cyclic backbone, should favour the G-quadruplex formation, stabilizing it and thus enhancing its target affinity. This approach has been extensively adopted in the past to improve the general properties of peptides ${ }^{9}$ and peptidomimetics, ${ }^{10}$ as well as peptide nucleic acids (PNA) ${ }^{11}$ and glycomimetics, ${ }^{12}$ but only limitedly applied to oligonucleotides ${ }^{13}$ in general, and, to the best of our knowledge, essentially unexploited thus far on aptamers.

In particular, in this work we report the design, synthesis and biophysical characterization of an unprecedented cyclic TBA analogue, here named cycTBA (Fig. 1), realized as a proof of concept to validate the efficacy of cyclization approaches applied to aptamers. cycTBA - carrying a 20 atoms linker connecting the two extremities of the oligonucleotide, which in the folded G-quadruplex conformation point in the same direction, far away from both the TT loops recognized by the protein - was successfully synthesized combining standard phosphoramidite solid phase synthesis and $\mathrm{Cu}(\mathrm{I})$-assisted azide-alkyne cyclization protocols (Fig. 1). In detail, this TBA analogue was prepared starting from the azide-functionalized solid support $\mathbf{1}^{14}$ and, after oligonucleotide assembly realized using standard phosphoramidite chemistry, a pentynyl group ${ }^{14}$ was introduced at the 5' -end by reaction with phosphoramidite 2 . After full deprotection and release from solid support $\mathbf{3}$, cyclization of linear oligonucleotide 4 was performed by addition of $\mathrm{CuSO}_{4}$ and sodium ascorbate in a $\mathrm{K}^{+}$-containing solution, necessary to promote the G-quadruplex folding of the oligonucleotide and thus ensure the spatial proximity of its ends. The resulting cycTBA was purified by HPLC and then characterized by MALDI-TOF MS analysis, as well as, the regular TBA As observed previously the linear oligonucleotide 4 displayed a retention time in RP-HPLC (15.65 min) bigger than the cyclic one 5 (11.48 min). (Fig. S1 and S2).
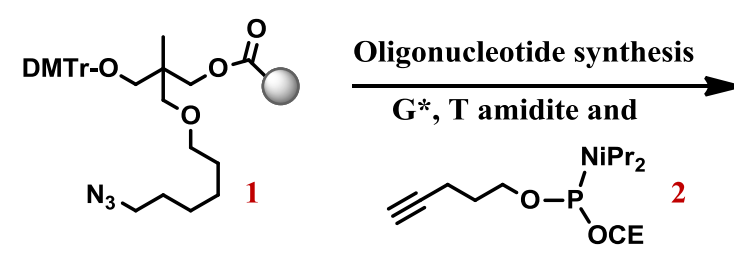

$$
\begin{aligned}
& \text { O CPG solid support } \\
& \text { DMTr }=4,4^{\prime} \text {-dimethoxytriphenylmethyl } \\
& \mathbf{G}^{*}=\mathbf{N}^{2} \text {-isobutyroyl deoxyguanosine } \\
& \text { CE }=\text { 2-cyanoethyl }
\end{aligned}
$$

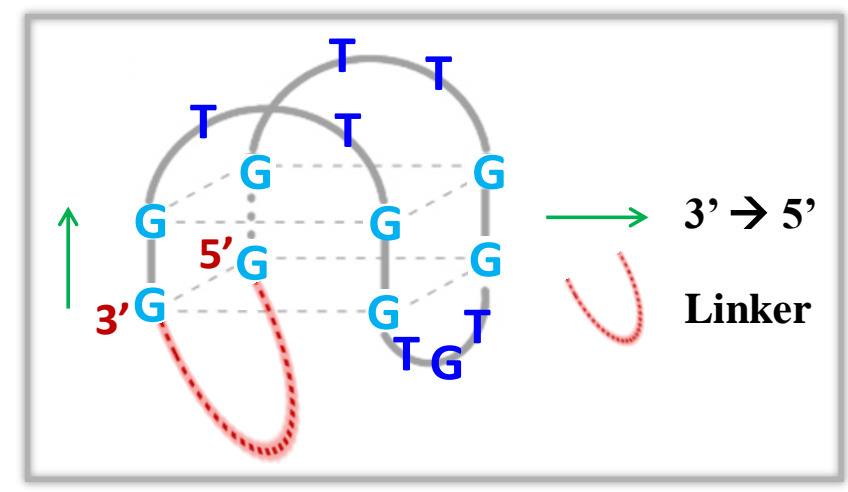

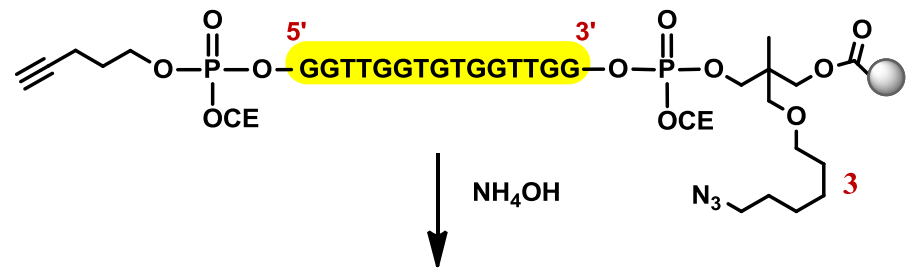
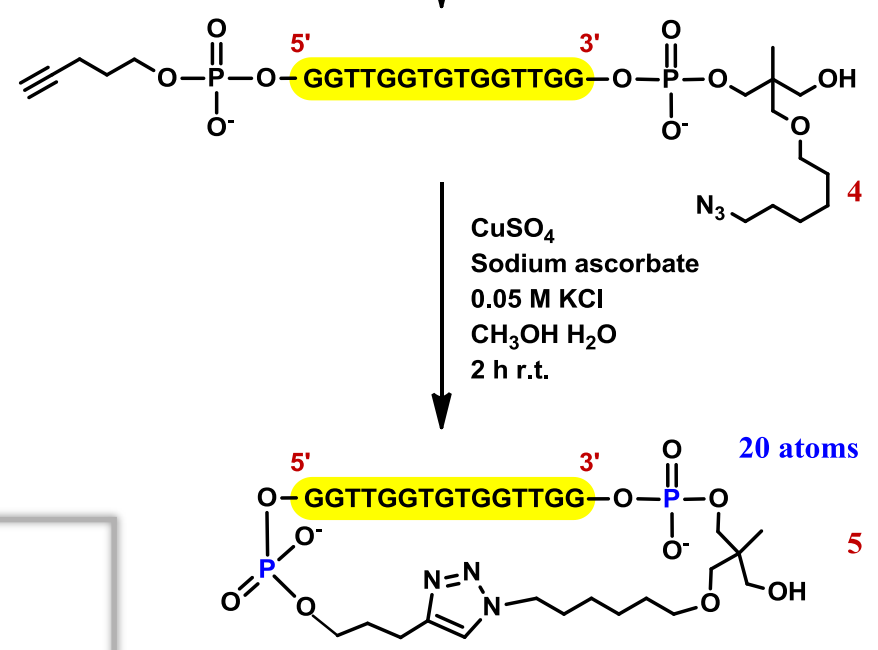
Figure 1. Synthetic scheme for the preparation of cycTBA. In the inset, a schematic representation of a cyclic TBA structure, with a generic linker connecting the 3'- and 5'-ends of the oligonucleotide sequence is reported.

Then, to get information on its conformational behaviour, the novel cyclic analogue was studied, in comparison with the unmodified TBA, by a combined approach including several techniques, i.e. UV, CD, CD-melting, differential scanning calorimetry (DSC), gel electrophoresis and SE-HPLC. In addition, its anticoagulant activity was determined by dynamic light scattering (DLS) analysis. In order to evaluate the effects of different saline conditions on the structuring ability of the aptamer, two different phosphate buffer solutions were analysed, containing a high content of $\mathrm{K}^{+}(10 \mathrm{mM}$ $\mathrm{KH}_{2} \mathrm{PO}_{4} / \mathrm{K}_{2} \mathrm{HPO}_{4}, 70 \mathrm{mM} \mathrm{KCl}, 0.2 \mathrm{mM}$ EDTA, $\mathrm{pH}$ 7.0, here indicated as $\mathrm{K}^{+}$buffer) or of $\mathrm{Na}^{+}$(i.e PBS: $137 \mathrm{mM} \mathrm{NaCl}, 2.7 \mathrm{mM} \mathrm{KCl}, 10 \mathrm{mM} \mathrm{Na} 2 \mathrm{HPO}_{4}, 1.8 \mathrm{mM} \mathrm{KH}_{2} \mathrm{PO}_{4}, \mathrm{pH} 7.2$, here indicated as $\mathrm{Na}^{+}$buffer), respectively mimicking the intracellular and extracellular media.

First of all, cycTBA and TBA samples were analysed by UV thermal difference spectra (TDS) at 2 $\mu \mathrm{M}$ concentration in both the selected $\mathrm{K}^{+}$and $\mathrm{Na}^{+}$buffers, recording spectra at low and high temperatures. The UV spectrum of cycTBA at $15{ }^{\circ} \mathrm{C}$, in both saline solutions, revealed the characteristic absorption of TBA, with the double-hump band between 230 and $300 \mathrm{~nm}$ (Fig. S3 and S4). The obtained TDS profile of cycTBA showed a positive band at $273 \mathrm{~nm}$ and a negative band at $295 \mathrm{~nm}$, similarly to unmodified TBA, providing the typical "fingerprint" of G-quadruplex structures (Fig. S3 and S4). ${ }^{15}$

Then, the conformational behaviour in solution of cycTBA was investigated by CD experiments at different concentrations, i.e. 2, 20 and $100 \mu \mathrm{M}$. The CD spectra at $15^{\circ} \mathrm{C}$ of cycTBA - here shown at $2 \mu \mathrm{M}$ conc. as a representative example - gave, in both $\mathrm{K}^{+}$and $\mathrm{Na}^{+}$buffer solutions, two positive bands, with maxima at about 295 and $246 \mathrm{~nm}$ and a negative band with a minimum at ca. $266 \mathrm{~nm}$ (Fig. 2a, dashed lines). These spectral features are consistent with those obtained for the unmodified TBA analysed under the same experimental conditions (Fig. 2a), and with those reported in the literature. ${ }^{16}$ Only a 2-3 nm shift was observed for the minimum (266 vs. $269 \mathrm{~nm}$ ) and the maximum ( 246 vs. $248 \mathrm{~nm}$ ) at low wavelengths with respect to TBA. These data confirmed that cycTBA is able to form a chair-like antiparallel G-quadruplex structure and that cyclization does not impair the G-quadruplex structuring ability of TBA nor affects its folding topology. Remarkably, in the $\mathrm{Na}^{+}$ buffer the cyclic aptamer exhibited a lower structuration degree than in the $\mathrm{K}^{+}$-rich solution, as expected considering that $\mathrm{K}^{+}$can stabilize $\mathrm{G} 4$ structures better than $\mathrm{Na}^{+}{ }^{+17}$

CD-melting experiments on cycTBA, monitoring at $295 \mathrm{~nm}$, provided a nice sigmoidal behaviour with apparent $\mathrm{T}_{\mathrm{m}}$ values of ca. 69 and $60{ }^{\circ} \mathrm{C}$, respectively in $\mathrm{K}^{+}$and $\mathrm{Na}^{+}$buffer solutions, indicating the formation of very stable $\mathrm{G} 4$ structures. The measured $\mathrm{T}_{\mathrm{m}}$ values were in very good agreement, within the experimental error, at all the analysed concentrations (Fig. 2, b and c). As expected, the cyclic structure allowed a marked increase of the G-quadruplex thermal stability of cycTBA, with $\Delta \mathrm{T}_{\mathrm{m}}=+18{ }^{\circ} \mathrm{C} v s$. unmodified TBA (Fig. 2, S5 and S6), analysed under the same experimental conditions at $2 \mu \mathrm{M}$ conc. $\left(69 v s .51{ }^{\circ} \mathrm{C}\right.$ and $60 v s$. $42{ }^{\circ} \mathrm{C}$, respectively in $\mathrm{K}^{+}$and $\mathrm{Na}^{+}$buffer solutions). In all cases, the heating and cooling profiles were essentially superimposable, indicating that, under the experimental conditions used (scan rate of $1{ }^{\circ} \mathrm{C} / \mathrm{min}$ ), the related denaturation/renaturation processes were reversible (Fig. S5 and S6). The melting curves were also studied by van't Hoff analysis, allowing $\mathrm{T}_{\mathrm{m}}$ values consistent with those estimated from the maxima of the first derivative plots. All the thermodynamic values obtained from the CD measurements at 2 $\mu \mathrm{M}$ conc. are shown in Table 1 . CD spectra were also acquired every $5{ }^{\circ} \mathrm{C}$ during the melting and cooling experiments (Fig. S7 and S8) showing a marked reduction of the CD signals at high temperatures, overall indicating that, from a qualitative point of view, cycTBA behaved as unmodified TBA in both saline phosphate buffer solutions. Notably, cycTBA was fully denaturated at $90{ }^{\circ} \mathrm{C}$ and, after the heating/cooling processes, full recovery of its spectral features was always observed (Fig. S7 and S8). 
a)

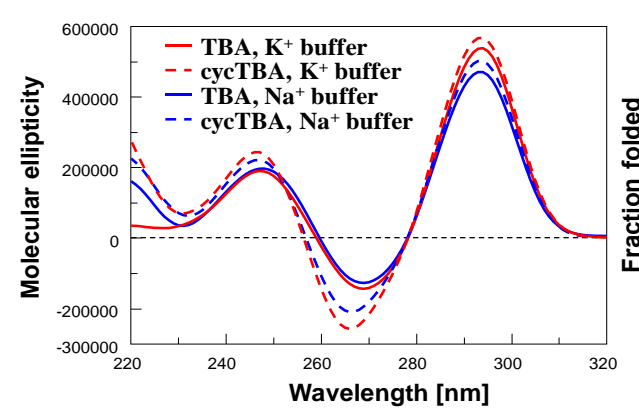

b)

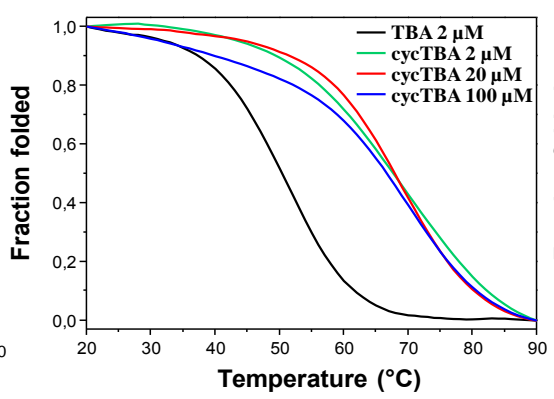

c) $\quad \mathrm{Na}^{+}$buffer

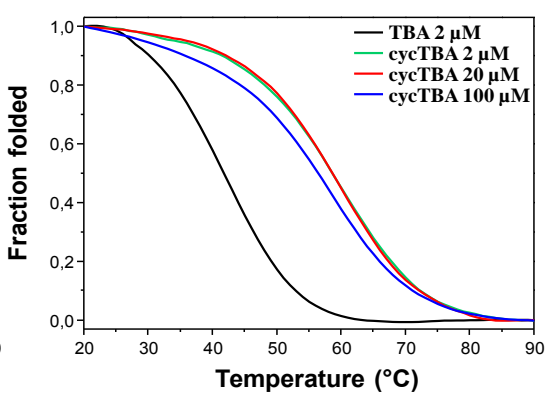

Figure 2. (a) overlapped CD spectra of TBA and cycTBA (continuous and dashed lines, respectively) at $15{ }^{\circ} \mathrm{C}$ and $2 \mu \mathrm{M}$ conc. both in $\mathrm{K}^{+}$and $\mathrm{Na}^{+}$buffer solutions (red and blue lines, respectively). (b, c) Overlapped CD-melting profiles (recorded at $295 \mathrm{~nm}$, with a temperature scan rate of $1{ }^{\circ} \mathrm{C} / \mathrm{min}$ ) reporting the fraction of folded cycTBA oligonucleotide as a function of the temperature at three different conc. $(2,20$ and $100 \mu \mathrm{M}$ : green, red and blue lines, respectively) in both the selected $\mathrm{K}^{+}(\mathbf{b})$ and $\mathrm{Na}^{+}$(c) buffer solutions, in comparison to unmodified TBA (analysed at $2 \mu \mathrm{M}$ conc., black line).

Inspection of the thermodynamic parameters for cycTBA unfolding compared with TBA (Table 1) revealed that the higher thermal stability of cycTBA in both buffer solutions was mainly due to a decrease of the unfolding entropy change. This is likely the thermodynamic consequence of the structural preorganization of the aptamer, imposed by its cyclic backbone, to form the proper Gquadruplex structure.

The thermodynamics of cycTBA unfolding was further investigated by differential scanning calorimetry. A noteworthy advantage of DSC measurements, with respect to spectroscopic methodologies, is that the thermodynamic parameters for the unfolding process can be obtained from experimental curves without any model assumption, whereas van't Hoff analysis of the spectroscopic melting profiles involves assuming a two-state process. The thermograms of cycTBA in both buffer solutions showed an almost symmetric shape and were fully reversible (Fig. S9). The measured enthalpy and entropy changes (Table S1) were very close to the values determined by the $\mathrm{CD}$ melting experiments, suggesting that the two-state assumption for the unfolding process was correct. Notably, the $\mathrm{T}_{\mathrm{m}}$ values were in very good agreement with those obtained by $\mathrm{CD}$ measurements, thus providing a strong evidence of the monomolecular nature of the observed transitions.

\begin{tabular}{|c|c|c|c|}
\hline & \multicolumn{3}{|c|}{$\mathbf{K}^{+}$buffer } \\
\hline & $T_{m}\left({ }^{\circ} C\right) \pm 1$ & $\Delta \mathrm{H}_{\mathrm{v} . \mathrm{H}}\left(\mathrm{kJ} \mathrm{mol}^{-1}\right)$ & $\Delta S_{\mathrm{v} \cdot \mathrm{H}}\left(\mathrm{kJ} \mathrm{mol}^{-1} \mathrm{~K}^{-1}\right)$ \\
\hline TBA & 51 & 152 & 0.47 \\
\hline \multirow[t]{3}{*}{ сустBA } & 69 & 135 & 0.39 \\
\hline & \multicolumn{3}{|c|}{$\mathrm{Na}^{+}$buffer } \\
\hline & $\mathbf{T}_{\mathrm{m}}\left({ }^{\circ} \mathbf{C}\right) \pm \mathbf{1}$ & $\Delta \mathrm{H}_{\mathrm{v} . \mathrm{H}}\left(\mathrm{kJ} \mathrm{mol}^{-1}\right)$ & $\Delta S_{\mathrm{v} \cdot \mathrm{H}}\left(\mathrm{kJ} \mathrm{mol}^{-1} \mathrm{~K}^{-1}\right)$ \\
\hline TBA & 42 & 147 & 0.47 \\
\hline сусТВА & 60 & 122 & 0.37 \\
\hline
\end{tabular}

Table 1. Apparent $T_{m}$ values (estimated from the maxima of the first derivative plots) and thermodynamic parameters for the unfolding process of TBA and cycTBA as determined by means of CD measurements at $295 \mathrm{~nm}$ in both saline phosphate buffer solutions at $2 \mu \mathrm{M}$ concentration. Errors on thermodynamic parameters are within $10 \%$. 
Gel electrophoresis analysis was used to further characterize cycTBA in the selected buffer solutions. Different oligonucleotide concentrations, ranging from 20 to $100 \mu \mathrm{M}$, were explored. In Fig. S10 a representative example of a $15 \%$ polyacrylamide gel, run under native conditions, is reported. In comparison with TBA, also cycTBA migrated as a single band on the gel, but with a slightly increased mobility, indicating that the cyclization provided the aptamer with a more compact structure, however with similar overall size in both the selected buffers (Fig. S10a). Remarkably, no retarded bands, attributable to large aggregates or higher order G4 structures, were detected even at the highest investigated concentrations (Fig. S10b). Therefore, it can be concluded that the cycTBA behaviour was not dependent on the sample concentration and a single unimolecular G-quadruplex structure was formed in all cases, in accordance with the CD-melting data acquired at different concentrations.

In order to further investigate the conformational behaviour of the novel cyclic TBA, also a size exclusion chromatography (SE-HPLC) study was carried out. Analysis of cycTBA at $2 \mu \mathrm{M}$ concentration showed only one peak in both buffer solutions, with retention times similar to those found for unmodified TBA ( $t_{\mathrm{R}} \mathrm{ca} .9 \mathrm{~min}$, Fig. S11). These data are consistent with the presence of a single, monomolecular G-quadruplex structure, under the tested conditions, for both the modified and unmodified TBA, in accordance with native PAGE experiments.

As a main requirement for potential in vivo uses, TBA analogues have to show a notably increased resistance to nuclease degradation $v s$. unmodified TBA. Therefore, the nuclease resistance of cycTBA was studied in PBS buffer containing $80 \%$ fetal bovine serum, i.e. a solution mimicking the extracellular environment in which the aptamer should exert its activity - in order to evaluate the protective effects of cyclization against enzymatic digestion of the oligonucleotide. Thus in parallel experiments, cycTBA and TBA were incubated in $80 \%$ fetal bovine serum at $37{ }^{\circ} \mathrm{C}$ and, at fixed times, aliquots of these mixtures were collected and analysed both by HPLC on a Nucleogen SAX column and gel electrophoresis analysis until disappearance of the peak or the band corresponding to the pure oligonucleotide.

Inspection of the chromatograms showed for the unmodified TBA the complete disappearance of the initial peak within $5 \mathrm{~h}$ (Fig. S12), while cycTBA was still present even after 7 days (Fig. 3). These results, also confirmed by gel electrophoresis analysis (data not shown), nicely demonstrated that cycTBA showed a markedly enhanced nuclease resistance, with $\mathrm{t}_{1 / 2}$ of $100 \mathrm{~h} v \mathrm{~s}$. $0.56 \mathrm{~h}$ for TBA, i.e. ca. 180-fold higher serum stability than TBA (Fig. 3 and S12). The high resistance to enzymatic degradation of cycTBA is clearly attributable to the presence of the linker connecting the 3'- and 5'-oligonucleotide ends, thus not accessible to exonucleases, and is highly desirable for potential in vivo studies.

\section{cycTBA}

a)

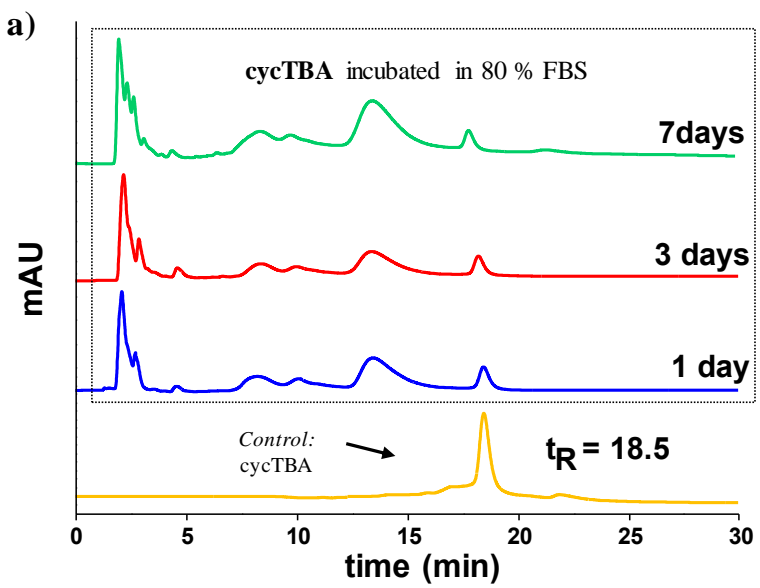

b)

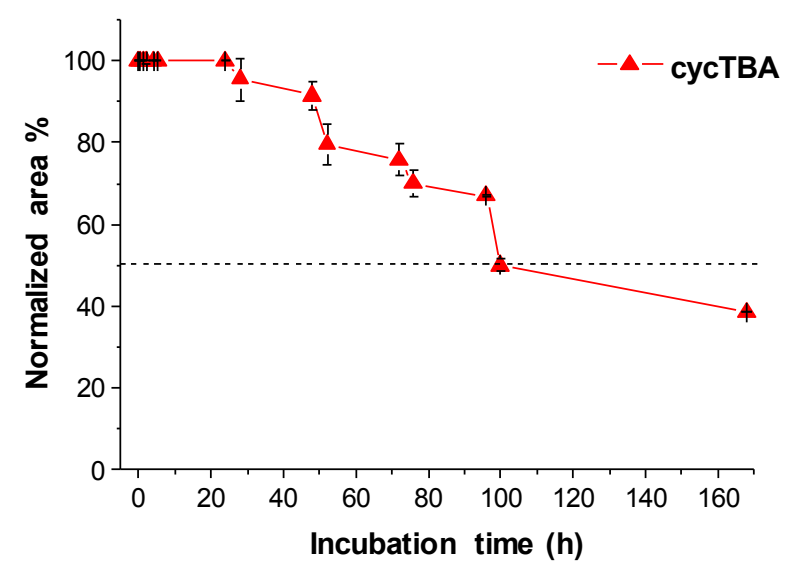


Figure 3. Enzymatic resistance experiments on cycTBA in $80 \%$ fetal bovine serum (FBS) as monitored by SAX-HPLC analysis: (a) representative chromatograms of the oligonucleotide alone (yellow line) and of the reaction mixtures in FBS analysed at 1, 3 and 7 days after incubation (blue, red and green lines, respectively); (b) chromatographic peak area expressed as percentage of the remaining area normalized to the initial one for all the analysed time points ( 15 total time points in 7 days). Data are reported as mean values \pm SD. The dark dashed line represents the $50 \%$ remaining area and thus the half-life $\left(\mathrm{t}_{1 / 2}\right)$ in hours.

The inhibitory activity towards human $\alpha$-thrombin was then determined by DLS experiments, following the conversion of fibrinogen into fibrin promoted by the protein, which results in a significant increase of light scattered intensity. In Fig. S13 the normalized scattered intensity is reported as a function of time for the system containing only fibrinogen and thrombin and for those containing also TBA and cycTBA, in a thrombin:aptamer ratio of 1:5. In the first case, the steep increase of intensity confirmed the quick formation of fibrin, which, on the contrary, was reduced by addition of the aptamers, as proved by the longer lag times and the lowest slope of the curves. Notably, in the presence of cycTBA, a higher intensity increase was observed than in the presence of TBA, suggesting that the former may be a less effective inhibitor than the latter. A proper comparison of their anticoagulant efficiency was performed by calculating the ratio between the initial slope of the normalized scattered intensities in the absence and in the presence of the aptamers, ${ }^{18}$ and indeed cycTBA showed an inhibitory effectiveness that is $55 \%$ that of TBA $(5 \pm 1$ vs $9 \pm 1$ for cycTBA and TBA respectively).

In conclusion, cycTBA exhibited an exceptional thermal stability $\left(\Delta \mathrm{T}_{\mathrm{m}}\right.$ of ca. $+18{ }^{\circ} \mathrm{C}$ in both $\mathrm{Na}^{+}$ and $\mathrm{K}^{+}$saline conditions) and notably increased nuclease resistance (ca. 180-fold higher) compared to unmodified TBA, however associated with a thrombin inhibition activity - as evaluated by DLS experiments - ca. half of that found for unmodified TBA. This is a relevant result, plausibly attributable to the increased rigidity of the G-quadruplex core induced upon cyclization of the aptamer.

Thus, not always higher stability and structural preorganization provide better biological results. These data seem to indicate that what could be more relevant for TBA bioactivity is the mutual interaction between the aptamer and the protein, as also suggested by other research groups. ${ }^{5 a}$ Probably once thrombin recognizes the aptamer, there is a conformational rearrangement upon complexation for best interaction, which could be somehow impaired if the aptamer is too rigidified.

Taken together, our results clearly demonstrated the favourable impact of cyclization on the physico-chemical features of TBA, opening new possible routes to the development of improved TBA analogues on varying the length and chemical features of the linker used to covalently bind the oligonucleotide extremities. Ongoing studies are currently devoted to obtain a fine-tuning of the linker features, so to successfully extend the cyclization approach to other biologically relevant Gquadruplex-based aptamers.

There are no conflicts to declare.

This work was supported by the Italian Association for Cancer Research (AIRC) (IG2015 n. 17037 to D. M.). F.M. is member of Inserm.

\section{References:}

1 a) J. A. Huntington and T. P. Baglin, Trends Pharmacol. Sci., 2003, 24, 589-595; b) E. Di Cera, Mol. Aspects Med., 2008, 29, 203-254; c) L. G. Licari and J. P. Kovacic, J. Vet. Emerg. Crit. Care, 2009, 19, 11-22; d) Zavyalova, N. Ustinov, A. Golovin, G. Pavlova and A. Kopylov, Curr. Med. Chem., 2016, 23, 2230-2244.

2 a) J. Hirsh, Thromb. Res., 2003, 109, S1-S8; b) S. Rangarajan, Haemophilia, 2011, 17, 90-94; c) B. L. 
Davidson, Chest, 2015, 147, 21-24.

3 a) L. C. Bock, L. C. Griffin, J. A. Latham, E. H. Vermaas and J. J. Toole, Nature, 1992, 355, 564-566; b) R. F. Macaya, P. Schultze, F. W. Smith, J. A. Roet and J. Feigon, Proc. Natl. Acad. Sci. U. S. A., 1993, 90, 3745-3749; c) K. Padmanabhan, K. P. Padmanabhan, J. D. Ferrara, J. E. Sadler and A. Tulinsky, J. Biol. Chem., 1993, 268, 17651-17654; d) I. Russo Krauss, A. Merlino, C. Giancola, A. Randazzo, L. Mazzarella and F. Sica, Nucleic Acids Res., 2011, 39, 7858-7867; e) I. Russo Krauss, A. Merlino, A. Randazzo, E. Novellino, L. Mazzarella and F. Sica, Nucleic Acids Res., 2012, 40, 8119-8128.

4 A. Schwienhorst, Cell. Mol. Life Sci., 2006, 63, 2773-2791.

5 a) I. Smirnov and R. H. Shafer, Biochemistry, 2000, 39, 1462-1468; b) L. Martino, A. Virno, A. Randazzo, A. Virgilio, V. Esposito, C. Giancola, M. Bucci, G. Cirino and L. Mayol, Nucleic Acids Res., 2006, 34, 6653-6662; c) A. Pasternak, F. J. Hernandez, L. M. Rasmussen, B. Vester and J. Wengel, Nucleic Acids Res., 2011, 39, 1155-1164; d) A. Aviñó, C. Fàbrega, M. Tintoré and R. Eritja, Curr. Pharm. Des., 2012, 18, 2036-47; e) N. Borbone, M. Bucci, G. Oliviero, E. Morelli, J. Amato, V. D’Atri, S. D. D'Errico, V. Vellecco, G. Cirino, G. Piccialli, C. Fattorusso, M. Varra, L. Mayol, M. Persico and M. Scuotto, J. Med. Chem., 2012, 55, 10716-10728; f) S. De Tito, F. Morvan, A. Meyer, J. J. Vasseur, A. Cummaro, L. Petraccone, B. Pagano, E. Novellino, A. Randazzo, C. Giancola and D. Montesarchio, Bioconjugate Chem., 2013, 24, 1917-1927; g) A. Virgilio, L. Petraccone, V. Vellecco, M. Bucci, M. Varra, C. Irace, R. Santamaria, A. Pepe, L. Mayol, V. Esposito and A. Galeone, Nucleic Acids Res., 2015, 43, 10602-10611; h) L. J. Aaldering, V. Poongavanam, N. Langkjær, N. A. Murugan, P. T. Jørgensen, J. Wengel and R. N. Veedu, ChemBioChem, 2017, 18, 755-763.

6 a) M. V. Yigit, D. Mazumdar and Y. Lu, Bioconjugate Chem., 2008, 19, 412-417; b) J. M. Yu, L. R. Yang, X. F. Liang, T. T. Dong and H. Z. Liu, Analyst, 2015, 140, 4114-4120; c) Y. C. Shiang, C. C. Huang, T. H. Wang, C. W. Chien and H. T. Chang, Adv. Funct. Mater., 2010, 20, 3175-3182.

7 a) Y. C. Shiang, C. L. Hsu, C. C. Huang and H. T. Chang, Angew. Chem. - Int. Ed. Eng., 2011, 50, 76607665; b) C. L. Hsu, H. T. Chang, C. T. Chen, S. C. Wei, Y. C. Shiang and C. C. Huang, Chem. Eur. J., 2011, 17, 10994-11000; c) S. S. Huang, S. C. Wei, H. T. Chang, H. J. Lin and C. C. Huang, J. Control. Release, 2016, 221, 9-17.

8 a) L. Gao, Y. Cui, Q. He, Y. Yang, J. Fei and J. Li, Chem. Eur. J., 2011, 17, 13170-13174; b) E. Babu, P. M. Mareeswaran and S. Rajagopal, J. Fluoresc., 2013, 23, 137-146; c) Q. Yue, T. Shen, L. Wang, S. Xu, H. Li, Q. Xue, Y. Zhang, X. Gu, S. Zhang and J. Liu, Biosens. Bioelectron., 2014, 56, 231-236; d) C. Riccardi, I. Russo Krauss, D. Musumeci, F. Morvan, A. Meyer, J. J. Vasseur, L. Paduano and D. Montesarchio, ACS Appl. Mater. Interfaces, 2017, 9, 35574-35587.

9 N. Riahifard, S. Mozaffari, T. Aldakhil, F. Nunez, Q. Alshammari, J. Yamaki, K. Parang and R. K. Tiwari, Molecules, 2018, 23, 2722.

10 N. Qvit, S. J. S. Rubin, T. J. Urban, D. Mochly-Rosen and E. R. Gross, Drug Discov. Today, 2017, 22, 454-462.

11 L. Moggio, L. De Napoli, B. Di Blasio, G. Di Fabio, J. D’Onofrio, D. Montesarchio and A. Messere, Org. Lett., 2006, 8, 2015-2018.

12 C. Coppola, V. Saggiomo, G. Di Fabio, L. De Napoli and D. Montesarchio, J. Org. Chem., 2007, 72, 9679-9689.

13 L. De Napoli, A. Messere, D. Montesarchio, G. Piccialli, C. Santacroce and G. M. Bonora, Nucleosides and Nucleotides, 1993, 12, 21-30.

14 G. Pourceau, A. Meyer, J. J. Vasseur and F. Morvan, J. Org. Chem., 2009, 74, 6837-6842.

15 a) J. Mergny, A. Phan and L. Lacroix, FEBS Lett., 1998, 435, 74-78; b) J. L. Mergny, J. Li, L. Lacroix, S. Amrane and J. B. Chaires, Nucleic Acids Res., 2005, 33, 1-6; c) J. Mergny and L. Lacroix, Curr. Protoc. Nucleic Acid Chem., 2009, 37, 17.1.1-17.1.15; d) M. Malgowska, D. Gudanis, A. Teubert, G. Dominiak and Z. Gdaniec, J. Biotechnol. Comput. Biol. Bionanotechnol., 2012, 93, 381-390.

16 a) S. Paramasivan, I. Rujan and P. H. Bolton, Methods, 2007, 43, 324-331, b) M. Vorlíčková, I. Kejnovská, J. Sagi, D. Renčiuk, K. Bednářová, J. Motlová and J. Kypr, Methods, 2012, 57, 64-75.

17 a) C. C. Hardin, T. Watson, M. Corregan and C. Bailey, Biochemistry, 1992, 31, 833-841; b) N. V Hud, F. W. Smith, F. A. L. Anet and J. Feigon, Biochemistry, 1996, 35, 15383-15390.

18 R. Troisi, V. Napolitano, V. Spiridonova, I. Russo Krauss and F. Sica, Nucleic Acids Res., 2018, 1-9. 